\title{
Implementasi Pembelajaran Multimedia Interaktif Untuk Meningkatkan Semangat Belajar Anak Pada Kelurahan Sungaisibam
}

\author{
Khusnul Fikri $^{1}$, Bagas Tri Ramadana ${ }^{2}$ \\ ${ }^{1}$ Fakultas Ekonomi dan Bisnis, Universitas Muhammadiyah Riau \\ ${ }^{2}$ Fakultas Ilmu Komputer, Universitas Muhammadiyah Riau \\ Email : khusnulfikri@umri.ac.id
}

\begin{abstract}
The world is currently facing a global COVID-19 pandemic which has affected many aspects of this outbreak. One aspect that has an impact is the educational aspect, where the community is required to reduce activities outside the home and the face-to-face learning process at school is carried out online. Based on the results of the survey, the problems faced include: (1) Decreased enthusiasm for learning in children (2) Children are more likely to play games on smartphones. The solution is presented by creating interactive multimedia learning media. Interactive multimedia is a multimedia that is equipped with a control device that can be operated by the user, so that the user can choose what he wants for the next process. Interactive multimedia is packaged in android form, created using Microsoft Office Power Point 2016 software, iSpring Suite 10, and Web 2 APK. Contains material for Religious Education, Character Education, and Creativity Education, as well as learning videos and quizzes. This study aims to: (1) Increase children's enthusiasm for learning in RW 01 Sungaisibam Village, (2) Create Android-based Interactive Multimedia applications, and (3) Provide learning assistance to optimize online-based learning. This activity resulted in an android-based learning application 'Belajar Seru'. With this application, children's enthusiasm for learning increases, this can be seen from the enthusiasm of children in learning to use interactive multimedia learning.
\end{abstract}

Keywords: Multimedia, Interactive Multimedia, Learning Media, iSpring Suite 10

\begin{abstract}
Abstrak
Saai ini dunia sedang menghadapi pandemi global covid-19 yang mengakibatkan banyak aspek yang terdampak oleh wabah ini. Salah satu aspek yang berdampak yaitu aspek pendidikan, dimana masyarakat dituntut untuk mengurangi kegiatan diluar rumah serta proses tatap muka belajar di sekolah dilakukan secara /online. Berdasarkan hasil survei permasalahan yang dihadapi antara lain : (1) Berkurangnya semangat belajar anak (2) Anak lebih cenderung sering bermain game pada smartphone. Solusi yang dihadirkan dengan membuat media pembelajaran multimedia interaktif. Multimedia interaktif merupakan suatu multimedia yang dilengkapi dengan alat pengontrolan yang dapat dioperasikan oleh pengguna, sehingga pengguna dapat memilih apa yang dikehendaki untuk proses selanjutnya. Multimedia interaktif dikemas dalam bentuk android, dibuat dengan memanfaatkan software Microsoft Office Power Point 2016, iSpring Suite 10, dan Web 2 APK. Berisi materi Pendidikan Agama, Pendidikan Karakter, dan Pendidikan Kreativitas dilengkapi juga video pembelajaran dan kuis. Penelitian ini bertujuan untuk : (1) Meningkatkan semangat belajar anak pada RW 01 Kelurahan Sungaisibam, (2) Membuat aplikasi Multimedia Interaktif berbasis Android, dan (3) Melakukan pendampingan belajar guna mengoptimalkan pembelajaran berbasis online. Kegiatan ini menghasilkan aplikasi pembelajaran berbasis android bernama 'Belajar Seru'. Dengan aplikasi tersebut semangat belajar anak meningkat, hal ini dapat dilihat dari antusias anak dalam belajar menggunakan pembelajaran multimedia interaktif.
\end{abstract}

Kata Kunci: Multimedia, Multimedia Interaktif, Media Pembelajaran, iSpring Suite 10 


\section{PENDAHULUAN}

Pendidikan merupakan salah satu aspek penting dalam memajukan bangsa. Dengan pendidikan yang baik, maka dapat menghasilkan sumber daya manusia yang baik pula dan berkualitas. Pendidikan yang berkualitas harus mampu mencapai tujuan pendidikan sesuai UU RI tahun 2003 tentang Sistem Pendidikan Nasional yang menyebutkan bahwa: "Pendidikan Nasional berfungsi mengembangkan kemampuan dan membentuk watak serta peradaban bangsa yang bertujuan untuk mengembangkan potensi yang dimiliki peserta didik agar menjadi manusia yang berkualitas dengan ciri-ciri beriman bertaqwa kepada Tuhan Yang Maha Esa, berakhlak mulia, sehat, beriman, cakap, kreatif, mandiri, dan menjadi warga negara yang demokratis serta tanggung jawab.

Saat ini dunia sedang menghadapi pandemi global covid-19 yang mengakibatkan banyak aspek yang terdampak oleh wabah ini. Salah satu aspek yang berdampak yaitu aspek pendidikan. Dimana masyarakat dituntut untuk mengurangi kegiatan diluar rumah serta proses tatap muka belajar di sekolah dilakukan secara daring/online.

Berdasarkan survei, orang tua dan anak-anak pada RW 01 Kelurahan Sungaisibam kesusahan dalam menghadapi pembelajaran online/daring ini. Adapun masalah yang dihadapi antara lain berkurangnya semangat dan minat belajar anak, anak cenderung lebih sering bermain game pada smartphone orang tua, dan pembelajaran tidak berjalan maksimal.

Untuk mengatasi permasalahan tersebut kami memberikan solusi dengan menghadirkan media pembelajaran yang lebih menarik, agar anak anak merasa senang dan tertarik dalam mengikuti proses pembelajaran dan dapat menerima materi pelajaran dengan maksimal serta dapat membangkitkan semangat anak anak dalam belajar.

Media merupakan segala sesuatu yang dapat menyalurkan pesan, dan dapat merangsang pikiran, perasaan, dan keinginan siswa sehingga dapat mendorong terjadinya proses belajar [1]. Media pembelajaran merupakan segala sesuatu yang mampu menyampaikan atau menyalurkan informasi secara efektif dan efisien dalam kegiatan pembelajaran [2].

Multimedia adalah salah satu media pembelajaran yang menggabungkan beberapa elemen media yang dipresentasikan dalam media komputer [3].

Multimedia interaktif adalah suatu multimedia yang dilengkapi dengan alat pengontrolan yang dapat dioperasikan oleh pengguna, sehingga pengguna dapat memilih apa yang dikehendaki untuk proses selanjutnya. Contoh multimedia interaktif yaitu multimedia pembelajaran interaktif, aplikasi game dan lain sebagainya[4].

Berdasarkan diskusi peneliti maka solusi yang tepat untuk mengatasi permasalahan yang ada adalah dengan mengembangkan media pembelajaran yang dapat meningkatkan semangat belajar anak anak. Media pembelajaran yang dikembangkan disesuaikan dengan perkembangan siswa dan karakteristik era revolusi industri 4.0 [5]. Belajar menggunakan multimedia menyebabkan terjadinya pendekatan konstruktivis dalam proses belajar dimana mereka menjadi peserta aktif dan membangun pengetahuan mereka sendiri [6]. Maka berdasarkan kesepakatan media pembelajaran yang dikembangkan yaitu multimedia interaktif menggunakan software Microsoft Power Point dan iSpring Suite 10. Multimedia Interaktif ini dikemas dalam bentuk aplikasi yang dapat di instal pada smartphone android, untuk pembuatan nya peneliti menggunakan software Web 2 Apk.

Penelitian ini bertujuan untuk : (1) Meningkatkan semangat belajar anak-anak pada RW 01 Kelurahan Sungaisibam, (2) Membuat aplikasi Multimedia Interaktif berbasis android, dan (3) Melakukan pendampingan belajar guna 
mengoptimalkan pembelajaran berbasis online.

Penelitian terdahulu yang di lakukan oleh (Dwi Ariyanti, dkk 2020) menyatakan bahwa beberapa hasil penelitian yang dilakukan dalam pemanfaatannya pada dunia pendidikan adalah hasil belajar siswa yang menggunakan iSpring Suite dengan penyajian yang menarik dapat meningkatkan motivasi belajar peserta didik, media interaktif berbasis iSpring Suite dapat membantu siswa belajar dengan konkret.[7]

\section{METODE PENGABDIAN}

Dalam memecahkan permasalahan yang ada, maka akan dilaksanakan dalam beberapa tahapan kegiatan, antara lain :

2.1. Sosialisasi

Melakukan sosialisasi ke RW 01 Kelurahan Sungaisibam, Sosialisasi ini dilakukan untuk memaparkan program kerja yang akan dilaksanakan.

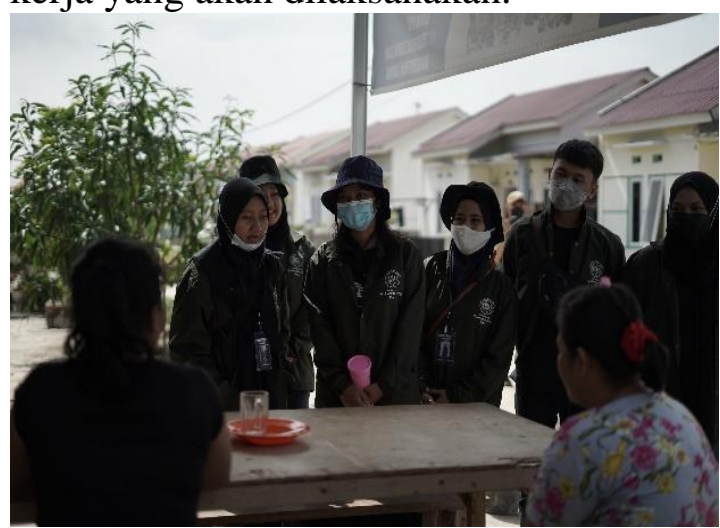

Gambar 1 Melakukan Sosialisai Kepada

Warga RW 01 Kelurahan Sungaisibam

2.2. Metode Pembelajaran Berbasis Multimedia

Melakukan pembelajaran dengan didukung multimedia (slide presentasi) untuk menyampaikan garis besar materi yang akan dimasukkan ke dalam aplikasi yang akan dibuat.

2.3. Alat dan Bahan

Adapun alat dan bahan yang di gunakan dalam pembuatan aplikasi adalah sebagai berikut :

1. Microsoft Office Power Point
Dalam kegiatan ini menggunakan Microsoft Office Power Point 2016 dengan alasan : (1) Mudah mengaplikasikannya, (2) Memudahkan dalam membuat desain multimedia interaktif, (3) Banyak fitur yang terdapat di dalamnya, antara lain: template, animasi, hyperlink, (4) integrasi dengan iSpring Suite 10. [8]

2. iSpring Suite 10

iSpring Suite merupakan salah satu tool yang mengubah file presentasi menjadi bentuk flash dan bentuk SCORM/AICC, yakni bentuk yang biasa digunakan dalam pembelajaran dengan e-learning LMS (Learning management System). iSpring secara mudah dapat diintegrasikan dalam Microsoft PowerPoint sehingga penggunaannya tidak membutuhkan keahlian yang rumit, sebagaimana dalam sebuah inovasi baru yang harus dilakukan. [9] Dalam iSpring juga dilengkapi fitur pembuatan quiz. Salah satu point penting di dalam aplikasi ispring adalah dalam pembuatan soal evaluasi dengan berbagai macam atau jenis pertanyaan atau soal seperti: True/False (Benar/Salah), Multiple Choice (Pilihan Ganda), Multiple response (Lebih dari satu pilihan), Type In (Isian Singkat), Matching (Menjodohkan), Sequence (Mengurutkan), Numeric (Klasifikasi), Fill in the Blank (Mengisi titik kosong), Multiple Choice Text (Pilihan ganda yang berupa isian singkat) [10]

3. Web 2 Apk

Software ini digunakan untuk menconvert multimedia interaktif ke dalam bentuk APK

2.4. Sosialisasi Aplikasi

Sosialisasi ini dilakukan kepada para orang tua anak-anak di RW 01 Kelurahan Sungaisibam. Sosialisasi yang dilakukan mencakup penjelasan tentang aplikasi, cara instalasi, dan cara penggunaan

\section{HASIL DAN PEMBAHASAN}

3.1.Sosialisasi dan Pembelajaran Berbasis Multimedia 
Tahap awal yang dilakukan adalah menemui ketua RW 01 Kelurahan Sungaisibam serta melakukan observasi ke lapangan untuk menggali informasi kepada orang tua dan anak-anak terkait masalah yang dihadapi dalam proses pembelajaran.

\subsection{Penyusunan Materi}

Setelah melakukan sosialisasi selanjutnya kegiatan yang dilakukan adalah membuat materi untuk bahan ajar. Dalam kegiatan ini ada 3 garis materi yang disampaikan yaitu Pendidikan Agama, Pendidikan Karakter, dan Pendidikan Kreativitas.

\subsection{Penyampaian Materi}

Kegiatan ini dilakukan untuk menyampaikan materi yang telah dibuat sebelumnya. Kegiatan ini dilakukan pada 3 RT yaitu di RT 03, RT 04, dan RT 05. Penyampaian materi ini juga di selingi oleh berbagai pernainan dan juga quiz untuk membuat suasana yang semangat, menarik, dan

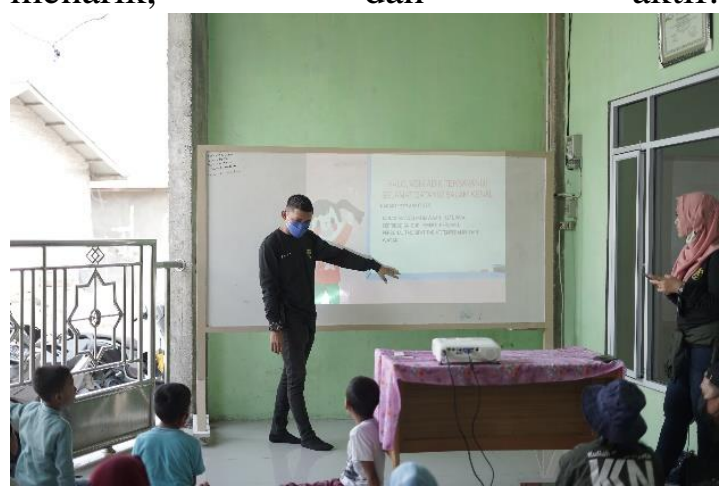

Gambar 2 Penyampaian Materi Kepada

Anak RW 01

\subsection{Pembuatan Aplikasi Multimedia} Interaktif

Aplikasi yang dibuat bernama 'Belajar Seru' di dalam nya terdapat 3 materi yaitu : Pendidikan Agama, Pendidikan Karakter, dan Pendidikan Kreativitas. Aplikasi ini dikemas dalam bentuk aplikasi android dan dilengkapi juga dengan video pembelajaran dan quiz terkait materi.

Untuk langkah-langkah pembuatan nya sebagai berikut :
1. Pembuatan materi dengan menggunakan Microsoft Office Power Point 2016

Pada langkah ini proses pembuatan slide dengan menambahkan beberapa karakter gambar dan juga memasukkan materi pembelajaran. Slide powerpoint di buat semenarik mungkin. Lalu pada powerpoint ini juga dilakukan proses hyperlink untuk membuat suatu tombol jika tombol tersebut di klik akan pindah ke slide selanjutnya, kemudian menonaktifkan on mouse click sehingga hanya tombol tertentu saja yang dapat di klik.

2. Pembuatan quiz menggunakan iSpring Suite 10

Quiz ini dibuat dalam bentuk multiple choice dan bersumber dari materi yang di muat dalam materi pembelajaran

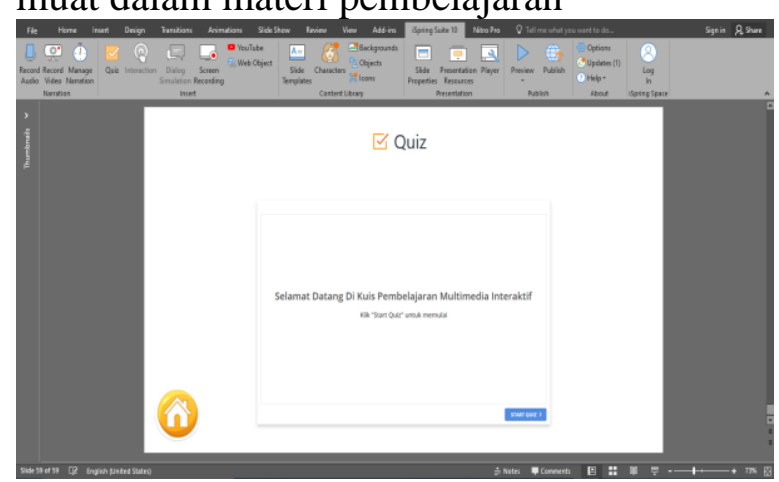

Gambar 3 Proses Pembuatan Quiz

Dengan iSpring Suite 10

3. Convert PPT ke HTML menggunakan iSpring Suite 10

Langkah berikutnya setelah selesai membuat materi dan juga quiz yaitu mengconvert file PPT yang sudah dibuat ke dalam bentuk HTML dengan menggunakan iSpring Suite 10.

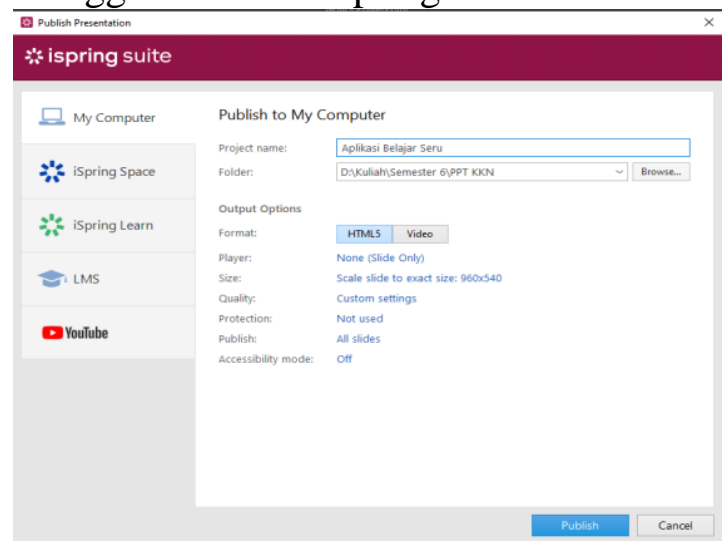

Gambar 4 Proses Konversi File PPT Menjadi HTML Dengan Menggunakan iSpring Suite 10 
4. Convert File HTML 5 ke APK dengan menggunakan Web 2 APK

Setelah file sudah menjadi HTML langkah selanjutnya adalah mengubah ke dalam bentuk APK, software yang digunakan adalah Web 2 APK. Hal yang di butuhkan dalam proses ini adalah gambar yang akan dijadikan icon untuk tampilan aplikasi.

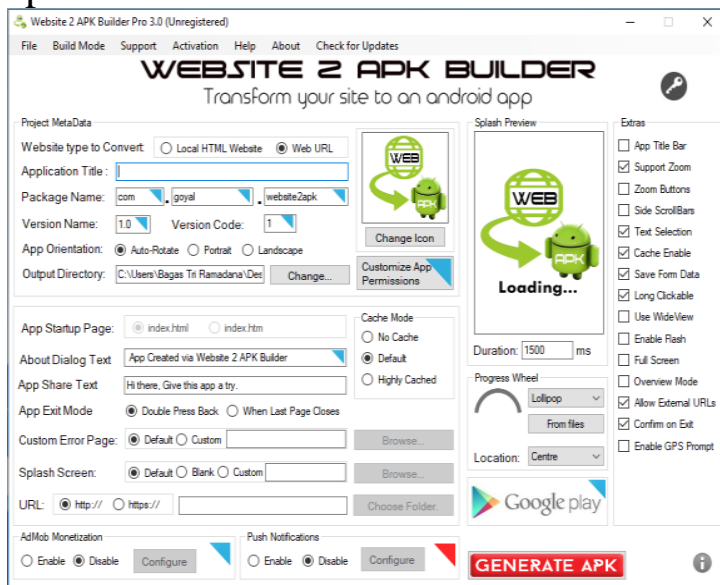

Gambar 5 Konversi file HTML menjadi

file APK menggunakan software Website

2 APK Builder

5. Uji Coba Instal Di Smartphone

Proses pengujian install aplikasi yang

sudah dibuat di smartphone.

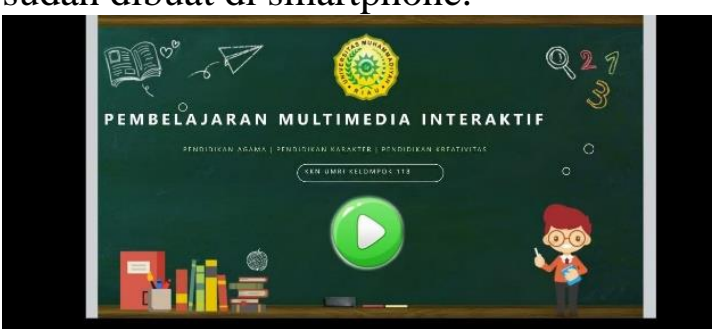

Gambar 6 Tampilan aplikasi di

smartphone

6. Publikasi Aplikasi

Aplikasi 'Belajar Seru' sudah selesai di buat dan dapat di download melalui link https://tinyurl/appmultimedia.com

\section{SIMPULAN}

\footnotetext{
Pembelajaran

Multimedia Interaktif telah berhasil di implementasikan pada RW 01 Kelurahan Sungaisibam Kecamatan Binawidya Kota Pekanbaru dan berjalan dengan cukup baik. Kegiatan pengabdian oleh tim Kuliah Kerja Nyata Kelompok 11B Universitas
}

Muhammadiyah Riau telah membantu meningkatkan semangat belajar anak-anak dengan menghadirkan Multimedia Interaktif. Hal ini dapat dilihat dari antusisas anak anak dalam belajar menggunakan multimedia interaktif dan berbasis android. Multimedia yang sudah dibuat berupa aplikasi android yang dapat di instal di smartphone orang tua. Aplikasi yang dibuat bernama 'Belajar Seru' yang berisi materi, video pembelajaran, dan kuis. Adapun materi nya berupa Pendidikan Karakter, Pendidikan Agama, dan Pendidikan Kreativitas. Proses pembuatannya menggunakan software Microsoft Office Power Point 2016, iSpring Suite 10, dan Web 2 Apk.

\section{UCAPAN TERIMAKASIH}

Ucapan terima kasih disampaikan kepada ketua RW 01, Orang Tua dan Anak- Anak di RW 01 Kelurahan Sungaisibam, Kecamatan Binawidya, Kota Pekanbaru, Ucapan terimakasih untuk seluruh anggota KKN UMRI kelompok 11B, Dosen Pembimbing Lapangan Bapak Khusnul Fikri, SE., MM serta Universitas Muhammadiyah Riau yang telah memberikan dukungan atas terselenggaranya kegiatan ini.

\section{DAFTAR PUSTAKA}

[1] T. rahmah Illahi, W. Sukartiningsih, and W. T. Subroto, "Pengembangan Multimedia Interaktif Pada Pembelajaran Materi Jenis-Jenis Pekerjaan Untuk Meningkatkan Kemampuan Berpikir Kritis Mahasiswa Program Pascasarjana , Prodi Pendidikan Dasar, Universitas Negeri Surabaya , Dosen Pascasarjana , Prodi Pendidikan Da," J. Kaji. Pendidik. dan Has. Penelit., vol. 4, no. 3, 2018.

[2] M. Istiqlal, "Pengembangan Multimedia Interaktif Dalam Pembelajaran Matematika," JIPMat, vol. 2, no. 1, 2017, doi: 
10.26877/jipmat.v2i1.1480.

[3] F. Armansyah, S. Sulton, and S. Sulthoni, "Multimedia Interaktif Sebagai Media Visualisasi DasarDasar Animasi," J. Kaji. Teknol. Pendidik., vol. 2, no. 3, pp. 224229, 2019 , doi: 10.17977/um038v2i32019p224.

[4] P. Manurung, "Multimedia Interaktif Sebagai Media Pembelajaran Pada Masa Pandemi Covid 19," Al-Fikru J. Ilm., vol. 14, no. 1, pp. 1-12, 2021, doi: 10.51672/alfikru.v14i1.33.

[5] U. N. Padang, "Edukatif: Jurnal Ilmu Pendidikan Pengembangan Multimedia Interaktif Menggunakan Software Macromedia Flash 8 Sebagai Upaya Meningkatkan Motivasi Belajar Siswa Sekolah Dasar Rahmad Wahyugi 1 $\square$, Fatmariza 2," Edukatif J. Ilmu Pendidik., vol. 3, no. 3, pp. 785-793, 2021, [Online]. Available:

https://doi.org/10.31004/edukatif.v 3i3.439.

[6] M. Jannah, A. Husna, and S. Nurhalimah, "Pembuatan Aplikasi Android dengan Cepat Menggunakan Ispring untuk Menunjang Pembelajaran Secara Daring," VEKTOR J. Pendidik. IPA, vol. 1, no. 2, pp. 66-72, 2020, doi: 10.35719/vektor.v1i2.8.

[7] D. Ariyanti, Mustaji, and Harwanto, "Multimedia Interaktif Berbasis Ispring Suite," Educ. Dev., vol. 8, no. 2, pp. 381-389, 2020.

[8] R. Monemi, Lufri, and I. Leilani, "Pengembangan Multimedia Interaktif Berbasis Power Point Disertai Games Kuis Course Maze Pada Materi Sistem Ekskresi Untuk Peserta Didik Kelas Viii Smp Developing Interactive Multimedia Based on Power Point With Course Maze Games Kuis About Excretion Syste," J. Biosains, vol. 1, no. 2, pp. 252-260, 2017, [Online].
Available:

http://ejournal.unp.ac.id/students/in dex.php/bio/issue/download/355/56

[9] S. Kudsiyah, "Pengembangan Multimedia Power Point Interaktif Materi Tata Urutan Peraturan Perundang-Undangan Nasional Kelas Viiid Smpn 1 Jabon," Kaji. Moral dan Kewarganegaraan, vol. 5, no. 01, pp. 1-15, 2017.

[10] M. Julianti and A. Arwin, "Pengembangan Media Pembelajaran Berbasis Android Menggunakan Powerpoint Ispring Suite 9 Pada Pembelajaran TematikTerpaduKelas IV Sekolah Dasar," J. Basic Educ. Stud., vol. 4, no. 1, pp. 888-896, 2021, [Online]. Available:

https://ejurnalunsam.id/index.php/j bes/article/view/3477. 